\title{
Oversecretion of glucagon by pancreases of ventromedial hypothalamic-lesioned rats: a re-evaluation of a controversial topic
}

\author{
F. Rohner-Jeanrenaud and B. Jeanrenaud \\ Laboratoires de Recherches Métaboliques, Geneva University Medical School, Geneva, Switzerland
}

\begin{abstract}
Summary. Glucagon secretion by perfused pancreases of control and ventromedial hypothalamic-lesioned rats was studied in response to a mixture of 20 different amino-acids used at physiological or pharmacological concentrations, and under experimental conditions near to or different from physiological situations. When experimental conditions are too extreme (lack of glucose with 5 or $15 \mathrm{mmol} / \mathrm{l}$ final amino-acid concentration), there was no difference of glucagon secretion between pancreases of control and ventromedial hypothalamiclesioned animals. However, when experimental conditions are as close as possible to those prevailing in vivo (presence of $5 \mathrm{mmol} / 1$ glucose with 2.5 or $5 \mathrm{mmol} / 1$ amino-acid concentration), pancreases from ventromedial hypothalamic-lesioned rats clearly oversecrete glucagon when compared with control
\end{abstract}

rats (with $2.5 \mathrm{mmol} / 1$ amino-acid: controls: 7.9 , ventromedialhypothalamic-lesioned: $17.1 \mathrm{ng} / 20 \mathrm{~min}, \quad p<0.05$; with $5 \mathrm{mmol} / 1$ amino-acid: controls: 12.6 , ventromedialhypothalamic-lesioned: $31.0 \mathrm{ng} / 20 \mathrm{~min}, p<0.025$ ). Upon extrapolating these results to a situation in vivo, this study indicates that ventromedial hypothalamic-lesioned rats secrete more glucagon than controls in response to physiological stimuli, at least at the level of the portal vein. This could explain why the lesioned rats, known to be hyperinsulinaemic, are nevertheless normoglycaemic and have increased plasma urea levels.

Key words: Perfused pancreas, ventromedial hypothalamic obesity, glucagon secretion, amino-acid mixture stimulation, glucose concentration.
Ventromedial hypothalamic (VMH) lesions are known to produce obesity in rats even in the absence of hyperphagia $[1,2]$. Furthermore, the increased fat accretion that follows VMH lesions has been ascribed to the presence of hyperinsulinaemia [1,2], a defect which appears within minutes after the lesions [3], leading to stimulation of most lipogenic pathways [1].

Amongst the many parameters which have been measured in VMH-lesioned rats some of them, in particular the increase in plasma urea levels [4] and normoglycaemia [1, 2], cannot be explained by hyperinsulinaemia. It has been shown previously that the increased plasma urea levels of VMH-lesioned rats were not due to impaired kidney function failing to excrete urea, nor to increased muscle or liver protein catabolism, nor to impaired amino-acid transport in the liver [4]. It was also observed that tyrosine aminotransferase and glutamate-oxaloacetate transaminase activities, as well as lipogenesis from amino-acids, were higher in livers of VMH-lesioned than in control rats [4]. These observations suggested, in the hepatocytes of VMH-lesioned rats, the presence of an increased deamination of amino-acids, providing the liver with increased amounts of nitrogen residues for urea synthesis and of metabolic intermediates for pathways, such as lipogenesis. In view of the known effects of glucagon in inducing the synthesis of tyrosine aminotransferase [5] and that of all five enzymes of the urea cycle [6], as well as in stimulating hepatic glucose production [7], it may be postulated that VMH-lesioned rats are not only hyperinsulinaemic but hyperglucagonaemic as well. This hypothesis is in keeping with the observations that the hyperinsulinaemia of VMH-lesioned rats is due to increased vagal tone on the endocrine pancreas $[2,3$, $8-10]$ and that a stimulation of the vagus, in normal animals, increases not only insulin but also glucagon output by the pancreas [11]. Thus if, as is now widely recognized, hyperactivity of the parasympathetic nervous system in VMH-lesioned rats is responsible for their hyperinsulinaemia $[2,3,8-10]$, one would also anticipate an increased glucagon secretion in these animals. However, the studies carried out on plasma glucagon levels or glucagon secretion in vitro in VMH-lesioned rats are still contradictory.

The aim of this study was to clarify the problem of glucagon secretion in VMH-lesioned rats. To do this, perfused pancreases of normal and VMH-lesioned rats were studied to assess portal levels of the hormone. 


\section{Materials and methods}

\section{Animals}

Eight to 10 -week-old female Sprague-Dawley-derived rats $(230-270 \mathrm{~g}$ body weight) were used. They were kept in animal quarters at a constant temperature $\left(23^{\circ} \mathrm{C}\right)$ with a fixed $(12 \mathrm{~h})$ light cycle. The animals were fed a standard laboratory chow containing $12 \% \mathrm{H}_{2} \mathrm{O}, 17 \%$ protids, $3 \%$ lipids, $58.7 \%$ glucids, $4.3 \%$ cellulose and $5 \%$ minerals (UAR Laboratories, Villemoisson, Epinay/Orge, France) and water ad libitum. Bilateral electrolytic lesions of the VMH area were performed as described elsewhere [12]. Both control and VMH-lesioned rats were subsequently allowed to feed freely for 3 days to select successfully lesioned animals by the occurrence of hyperphagia and increased body weight (mean excess in body weight over control rats after 3 days: $36.2 \pm 1.2 \mathrm{~g}, p<0.001, n=44)$. Following this, control and VMH-lesioned rats received the same amount of food for 4 days $(16 \mathrm{~g} /$ day $)$ given at identical intervals by an automatic food distributor (pairfeeding). VMH-lesioned animals that did not increase their body weight by at least $30 \mathrm{~g}$ during the first 3 days (control rats increased their body weight by $6-9 \mathrm{~g}$ during the same period), and which had basal plasma insulin levels lower than $6 \mathrm{ng} / \mathrm{ml}$ were discarded from the study.

\section{Methods}

At the end of this 7-day period, pancreases of control and VMH-lesioned rats were isolated and perfused as described elsewhere $[12,13]$. The perfusion medium was a Krebs-Ringer bicarbonate buffer, (pH 7.4-7.5) containing $0.4 \mathrm{~g} / 100 \mathrm{ml}$ human serum albumin (Red Cross, Berne, Switzerland) and iniprol (2000 antiprotease units/ml, Laboratoire Choay, Paris, France).

In the first series of experiments, pancreases were perfused for $30 \mathrm{~min}$ with $5 \mathrm{mmol} / 1$ glucose. The last $10 \mathrm{~min}$ of this equilibration period were used for measuring basal glucagon secretion. Following this, pancreases of control and VMH-lesioned rats were challenged for $20 \mathrm{~min}$ with a mixture of 20 amino-acids used at the relative proportions of those found in normal rat serum [14] and at the final concentration of $2.5,5$ and $15 \mathrm{mmol} / \mathrm{l}$, glucose remaining at $5 \mathrm{mmol} / 1$. In the second series of experiments, the equilibration period was the same as above except that no glucose was added. Subsequently, pancreases of control and lesioned animals were challenged with the same amino-acid mixture (final concentrations of $2.5,5$ and $15 \mathrm{mmol} /$ 1), but always in the absence of glucose.

The composition of the amino-acid mixture was as described elsewhere [15]. In all cases, $3 \mathrm{ml}$ sampies (1 min of sampling) were collected from the cannula placed in the portal vein, cooled on ice, then frozen at $-20^{\circ} \mathrm{C}$ until assayed. Fourteen samples were taken for each perfusion. Of these, three were collected to obtain the basal glucagon release levels (at time $-10,-5,0 \mathrm{~min}$ ). Following the infusion of the amino-acid mixture, samples were collected every minute for $6 \mathrm{~min}$, then every $5 \mathrm{~min}$ for the subsequent $14 \mathrm{~min}$ (stimulation period) as well as for the next $10 \mathrm{~min}$ when the amino-acid stimulation was discontinued. The rate of glucagon release was calculated by multiplying the concentration of the respective sample by the flow rate which was measured for each time interval. Net release during $20 \mathrm{~min}$ of exposure to a stimulus was obtained by calculating the total area minus baseline under the curve of glucagon output for each perfusion. All values are mean \pm SEM of five to eight pancreases, statistical analysis being carried out with the Student's one-tailed t-test for unpaired data.

\section{Immunoassay procedures}

Glucagon was measured according to Assan et al. [16], using the rabbit anti-glucagon antiserum BR 339 (kindly provided by Drs. Ph. Halban and A. E. Renold, Institut de Biochimie Clinique, Geneva, Switzerland). This antibody has been shown to cross-react $<1 \%$ with glycentin, gastric inhibitory polypeptide, gastrin, motilin, cholecysto- kinin-pancreozymin, secretin, vasoactive intestinal polypeptide, somatostatin, pancreatic polypeptide, and insulin. In our hands, however, this antibody permitted us to obtain linear serial dilutions of perfusate glucagon values only when the ethanol extraction of Heding was used [17]. Thus, when basal glucagon output by perfused pancreas $(5 \mathrm{mmol} / \mathrm{l})$ was measured at different dilutions in non-extracted perfusates, values were very scattered (between 0.28 and $1.05 \mathrm{ng}$ / min). On the contrary, extraction of perfusates with ethanol markedly decreased such dispersion $(0.10-0.15 \mathrm{ng} / \mathrm{min})$. As ethanol extraction has been shown to exclude 'big' glucagon and most of the $9000 \mathrm{~mol} w \mathrm{t}$ glucagon, the procedure allowed for the measurement of pancreatic glucagon ( $3500 \mathrm{~mol} \mathrm{wt}$ ) only. This shows, in non-extracted perfusates, the presence of a sizeable amount of non-pancreatic glucagon that erratically interferes with the radioimmunoassay and probably arises from the small part of the duodenum present in the preparation. For each assay, the yield of the extraction procedure was measured and was found to be $90-95 \%$. The values of perfusate glucagon were corrected for by the yield factor of each individual assay. In each assay, care was taken to randomize the samples of perfusate obtained from pancreases of control and VMH-lesioned rats perfused under different stimulation conditions.

Porcine glucagon (Novo Research Institute, Bagvaerd, Denmark) was used as standard and ${ }^{125} \mathrm{I}$-porcine glucagon as tracer (500-600 $\mathrm{uCi} / \mu g$; Centre National de Transfusion Sanguine, Orsay, France). For each assay, the tracer was purified using the talc technique of Rosselin et al. [18]. The standard curves were diluted using the same buffer as the perfusate, namely Krebs-Ringer bicarbonate buffer.

The lower limit of detection of the assay system was $15 \mathrm{pg} / \mathrm{ml}$. The standard deviation of the intra-assay was $3.0 \%$ and that of the interassay variability $13.4 \%$. When six serial dilutions of the same perfusate sample $(1: 20 ; 1: 10 ; 1: 5 ; 1: 4 ; 1: 2$, undiluted) were assessed in the same assay, the respective results differed by $2.4-10 \%$.

Finally, the amino-acid mixture was tested at all concentrations used for possible interference in the immunoassays; the results showed that this was not the case.

\section{Results}

\section{Amino-acid-induced glucagon output in the presence of glucose in the medium}

The results obtained by perfusing pancreases of control and pair-fed VMH-lesioned rats in the presence of a normal glucose concentration of $5 \mathrm{mmol} / 1$ and stimulating them with a mixture of 20 different amino-acids used at the final concentration of $2.5 \mathrm{mmol} / 1$ are shown in Figure 1. This concentration of amino-acids was chosen to mimic the lowest amino-acidaemia measured in arterial blood of normal rats fed a mixed diet (i.e. $2.85 \mathrm{mmol} / \mathrm{l}$ ) [19]. The presence of the amino-acids enhanced glucagon secretion in control pancreases, with a peak at 2 min followed by an almost negligible second phase, a secretory pattern observed previously by others using the same experimental approach [15]. More importantly, although basal glucagon output by pancreases of VMH-lesioned rats was the same than that of controls, their amino-acid-induced glucagon secretion was greatly increased, the oversecretion being more marked during the first $5 \mathrm{~min}$ of stimulation. When the effect of the amino-acid mixture was tested at greater concentrations ( 5 or $15 \mathrm{mmol} / 1$ - always in the presence of glucose $5 \mathrm{mmol} / \mathrm{l})$, the secretory pattern of glucagon 


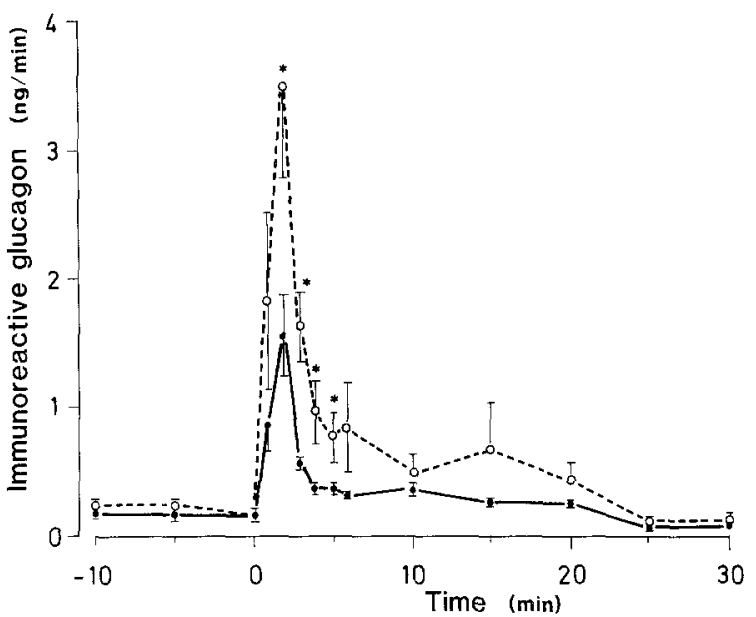

Fig. 1. Effect of a mixture of 20 different amino-acids at $2.5 \mathrm{mmol} / 1$ final concentration in the presence of $5 \mathrm{mmol} / 1$ glucose on glucagon secretion by perfused pancreases of control (solid line) and pair-fed VMH-lesioned rats (dotted line). Perfusion medium was a KrebsRinger bicarbonate buffer with human serum albumin $(0.4 \%)$ plus iniprol $(2,000$ antiprotease $\mathrm{U} / \mathrm{ml})$. Amino-acid mixture stimulation was from time 0 up to $20 \mathrm{~min}$. Basal immunoreactive glucagon secretion was identical in both groups: controls: $0.15 \pm 0.05 \mathrm{ng} / \mathrm{min}$; VMHlesioned: $0.20 \pm 0.06 \mathrm{ng} / \mathrm{min}, * 2 p$ at least $<0.05$. Each point is the mean \pm SEM of six (controls) and five (VMH-lesioned) experiments

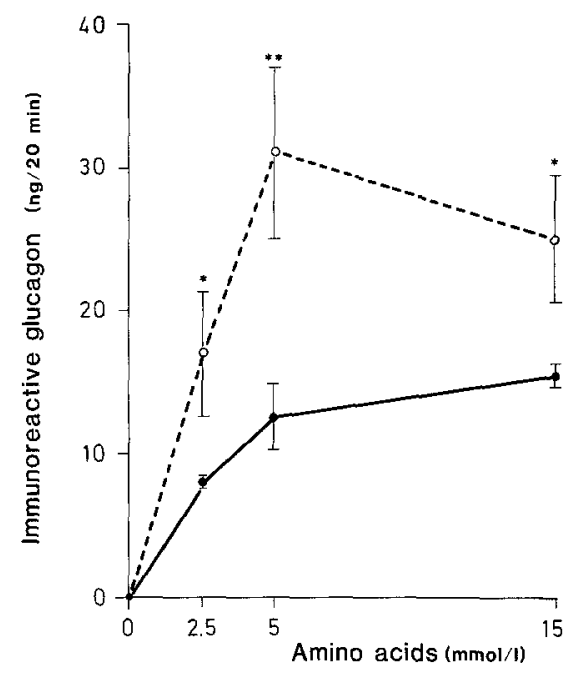

Fig. 2. Total glucagon secretion (above baseline) in response to final concentrations of $2.5,5$ and $15 \mathrm{mmol} / 1$ amino-acid mixture in the presence of $5 \mathrm{mmol} / \mathrm{l}$ glucose by perfused pancreases of control (solid line) and pair-fed VMH-lesioned rats (dotted line). Perfusion medium and timing of amino-acid mixture stimulation as in Figure $1 . * p<$ $0.05 ; * * p<0.025$. Each point is the mean \pm SEM of five to seven experiments

output was similar to that of Figure 1 (data not shown). Although these dynamic studies are not presented, they permitted the calculation of the net glucagon output by pancreases of the two groups of rats (Fig. 2). The pancreases of VMH-lesioned rats hypersecreted glucagon when compared to controls at the three different aminoacid concentrations tested $(2.5,5$ and $15 \mathrm{mmol} / \mathrm{l})$. Maximal stimulation was reached from $5 \mathrm{mmol} / \mathrm{l}$ aminoacid onward in the two groups, although clearly at a

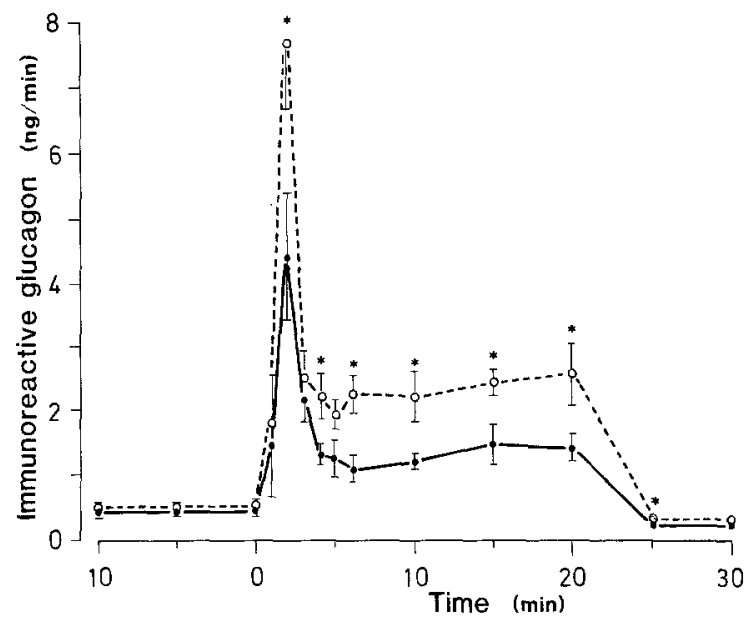

Fig. 3. Effect of a mixture of 20 different amino-acids at $2.5 \mathrm{mmol} / 1$ final concentration in the absence of glucose in the perfusate on glucagon secretion by perfused pancreases of control (solid line) and pair-fed VMH-lesioned rats (dotted line). Perfusion medium was as in Figure 1, except that glucose was omitted. Stimulation time: $20 \mathrm{~min}$ as in Figure 1. Basal immunoreactive glucagon secretion was identical in both groups: controls: $0.46 \pm 0.09 \mathrm{ng} / \mathrm{min}$; $\mathrm{VMH}$-lesioned: $0.50 \pm$ $0.06 \mathrm{ng} / \mathrm{min}, * 2 p$ at least $<0.05$. Each point is mean of five (control) and five (VMH-lesioned) experiments

Table 1. Total glucagon secretion (above baseline) in response to varying concentrations of a mixture of 20 different amino-acids in the absence of glucose by perfused pancreases of control and pair-fed VMH-lesioned rats

Final amino-acid Immunoreactive glucagon output ( $\mathrm{ng} / 20 \mathrm{~min}$ ) by concentration pancreases obtained from:

\begin{tabular}{lccl}
$(\mathrm{mmol} / \mathrm{l})$ & Control rats & $\begin{array}{l}\text { Pair-fed VMH- } \\
\text { lesioned rats }\end{array}$ & $p$ \\
\hline 2.5 & $37.8 \pm 4.6$ & $56.1 \pm 6.4$ & $<0.025$ \\
5 & $63.0 \pm 13.0$ & $74.5 \pm 10.6$ & NS \\
15 & $125.7 \pm 6.6$ & $103.5 \pm 10.3$ & NS
\end{tabular}

Results expressed as mean \pm SEM of five to eight experiments

higher level for the VMH-lesioned group. Of note is the observation that the $5 \mathrm{mmol} / \mathrm{l}$ concentration of aminoacid has been reported to prevail in arterial blood of normal rats after taking a mixed meal [19].

\section{Amino-acid-induced glucagon output in the absence of glucose in the medium}

Further experiments were conducted using increasing concentrations of the same amino-acid mixture but in the absence of glucose in the perfusion medium (Fig. 3, Table 1). The effect of the amino-acid mixture ( $2.5 \mathrm{mmol} / \mathrm{l}$ final concentration) in the absence of glucose on glucagon output by perfused pancreases of control and pair-fed VMH-lesioned rats is shown in Figure 3. As expected, the basal glucagon output of the two groups was higher in the absence than in the presence of glucose, although no inter-group difference was noted (Figs. 1 and 3). In control pancreases, the amino-acid 
mixture stimulated glucagon secretion to a greater degree in the absence than in the presence of glucose (Figs. 1 and 3) and a biphasic pattern, described previously and attributed to the lack of glucose [15], was now apparent. As further shown by Figure 3, although the qualitative pattern of glucagon secretion in response to the amino-acid stimulation was identical in both groups of rats, the amino-acid-induced glucagon output (at $2.5 \mathrm{mmol} / 1$ final concentration) was greater in pancreases of the VMH-lesioned group than in controls, during the first as well as the second phase of the hormonal response. In marked contrast, when the effect of higher amino-acid concentrations ( 5 and $15 \mathrm{mmol} / \mathrm{l}$ ) was tested, it was found that, although the dynamics of the release (not shown) remained similar to that illustrated by Figure 3, the total amount of glucagon secreted was now identical in the two groups (Table 1).

\section{Discussion}

Peripheral plasma glucagon levels have been found either slightly increased [20], unchanged [21, 22] or even somewhat decreased $[21,23,24]$ in VMH-lesioned compared with control rats. In this respect, the observation that glucagon clearance by the liver is linear as a function of the portal glucagon concentration up to very high level is of interest (C. Karakash, B. Jeanrenaud, unpublished data), since it is conceivable that increased portal glucagon levels in VMH-lesioned rats could prevail together with normal or near-normal peripheral glucagonaemia. As regard to portal output of the hormone in vivo, it should be mentioned that the only report which is available has shown, albeit following an unphysiological stimulation by a single amino-acid, arginine, an increased substrate-induced glucagon secretion in VMH-lesioned compared to control rats [25]. In vitro studies using perfused pancreases have been used as an indirect way of assessing portal levels of the hormone without interference by changes in blood flow. Nevertheless, the results obtained were again contradictory since both an increase $[12,26,27]$ and no change $[22,28]$ in glucagon secretion from pancreases of VMHlesioned rats have been reported. The main reason for these discrepancies could well lie in the fact that most previous studies were performed under extreme conditions, i. e., by using stimuli at pharmacological concentrations, by testing them as single substrate (e.g. arginine) or single hormone (e.g. adrenaline) and often, although not always, in the absence of glucose in the perfusion medium. The rationale for using these conditions was to amplify total glucagon output, overlooking the possibility that these conditions may potentially equalize differences between pancreases of control and VMH-lesioned rats.

The present data show that, when in vitro conditions clearly diverge too much from physiological ones (e.g. no glucose in the medium), pancreases of VMH-le- sioned rats oversecrete glucagon only at the low $(2.5 \mathrm{mmol} / \mathrm{l})$ final concentration of the amino-acid mixture, whereas the hormonal output in response to higher concentrations of the mixture ( 5 and $15 \mathrm{mmol} / \mathrm{l}$ ) is the same in the two groups. Under these conditions, the disappearance of inter-group differences can be explained by the fact that these rather unphysiological conditions result in increases in basal glucagon output and, following a stimulation by the amino-acid mixture, in a greater first phase together with the occurrence of a second phase glucagon secretion that is not observed when glucose is present in the medium. These upward shifts of glucagon secretion become large enough to obliterate the differences between pancreases of control and $\mathrm{VMH}$-lesioned rats in response to 5 and $15 \mathrm{mmol} / 1$ amino-acids. A similar upward shift of glucagon output could also prevail when a single amino-acid, such as arginine, is used as a stimulus at a pharmacological concentration $(19 \mathrm{mmol} / \mathrm{l})$, a situation which results in a marked, biphasic glucagon output that is no longer different between perfused pancreases of control and VMH-lesioned rats $[22,28]$.

In contrast to what has just been described, the present study demonstrates that, when tested in the presence of glucose $(5 \mathrm{mmol} / \mathrm{l})$ and in response to a stimulation by an amino-acid mixture used at concentrations known to occur in normal animals pre- or postprandially (2.5 and $5 \mathrm{mmol} / 1$, respectively) [19], pancreases from VMH-lesioned rats clearly oversecrete glucagon compared to controls. Under these conditions the hormonal response is monophasic in the two groups. The pharmacological concentration of $15 \mathrm{mmol} / 1$ amino-acid mixture is not more effective than $5 \mathrm{mmol} / \mathrm{l}$ in both groups, although the absolute values reached are still higher in pancreases of VMHlesioned rats. This is in keeping with the observation that near-maximal stimulation of glucagon output is produced by concentrations of amino-acid mixture corresponding to the upper levels of amino-acidaemia reached in vivo [15, 19].

Taken together, these data show that, when perfusion conditions are too distant from physiological ones, no difference of glucagon output between pancreases of control and $\mathrm{VMH}$-lesioned rats may be encountered. As several previous experiments were carried out in such situations, contradictory results may be expected and have indeed been found. More importantly, when perfusion conditions are chosen in such a way as to mimic physiological situations, it is clear that pancreases from VMH-lesioned rats oversecrete glucagon as compared with controls.

As hepatic glucagon clearance is linear up to very high levels of the hormone at the portal vein level, while such is not the case for insulin [29], the present data indicate that VMH-lesioned rats may be considered as animals with high portal and peripheral plasma insulin levels but with high glucagon levels only in the portal system. Apart from the insulin-resistant state of VMH- 
lesioned animals [1], this may yet be another reason why, despite their hyperinsulinaemia, VMH-lesioned animals are normoglycaemic $[1,2]$. It also explains why lesioned rats have increased plasma urea levels [4].

Acknowledgements. The authors express their gratitude to Mrs C. Barras for her excellent technical assistance and to Mrs A. M. Anselmo for assistance in setting up the glucagon radioimmunoassay. We thank Mrs C. McVeigh for typing the manuscript. This work has been supported by grants No 3.851 .0 .83 from The Swiss National Science Foundation, Berne, Switzerland, and by a grant-in-aid from Nestlé S. A., Vevey, Switzerland.

\section{References}

1. Assimacopoulos-Jeannet F, Jeanrenaud B (1976) The hormonal and metabolic basis of experimental obesity. Clin Endocrinol Metab 5: 337-365

2. Bray GA, York DA (1979) Hypothalamic and genetic obesity in experimental animals: an autonomic and endocrine hypothesis. Physiol Rev 59: 719-809

3. Berthoud HR, Jeanrenaud B (1979) Acute hyperinsulinemia and its reversal by vagotomy following lesions of the ventromedial hypothalamus in anesthetized rats. Endocrinology 105: 146-151

4. Karakash C, Rohner-Jeanrenaud F, Hustvedt BE, Jeanrenaud B (1980) Nitrogen handling in adult hypothalamic obese rats. Am J Physiol 238: E32-E37

5. Ernest MJ, Chen CL, Feigelson P (1977) Induction of tyrosine amino-transferase synthesis in isolated liver cell suspensions. Absolute dependence of induction on glucocorticoids and glucagon or cyclic AMP. J Biol Chem 252: 6783-6791

6. Snodgrass PJ, Lin RC, Müller WA, Aoki TT (1978) Induction of urea cycle enzymes of rat liver by glucagon. J Biol Chem 253: $2748-2753$

7. Stalmans W (1983) Glucagon and liver glycogen metabolism. In: Lefèbvre PJ (ed) Handbook of experimental pharmacology, vol 66. Springer, Berlin Heidelberg New York Tokyo, pp 291-314

8. Powley TL, Opsahl CA (1974) Ventromedial hypothalamic obesity abolished by subdiaphragmatic vagotomy. Am J Physiol 226: 25-33

9. Bray GA, Inoue S, Nishizawa Y (1981) Hypothalamic obesity. The autonomic hypothesis and the lateral hypothalamus. Diabetologia 20: $366-377$

10. Rohner-Jeanrenaud F, Bobbioni E, Ionescu E, Sauter JF, Jeanrenaud B (1983) Central nervous system regulation of insulin secretion. In: Szabo AJ (ed) Advances in metabolic disorders, vol 10. Academic Press, New York London, pp 193-220

11. Helman A, Marre M, Bobbioni E, Poussier Ph, Reach G, Assan R (1982) The brain-islet axis: the nervous control of the endocrine pancreas. Diabéte Mètab 8: 53-64

12. Rohner-Jeanrenaud F, Jeanrenaud B (1980) Consequences of ventromedial hypothalamic lesions upon insulin and glucagon secretion by subsequently isolated perfused pancreases in the rat. J Clin Invest 65:902-910

13. Assan R, Attali JR, Ballerio G, Boillot J, Girard JR (1977) Glucagon secretion induced by natural and artificial aminoacids in the perfused rat pancreas. Diabetes 26: 300-307

14. Scharff R, Wool IG (1964) Concentration of aminoacids in rat muscle and plasma. Nature (Lond) 202: 603-604
15. Pagliara A, Stillings SN, Hover B, Martin DM, Matschinsky FM (1974) Glucose modulation of aminoacid-induced glucagon and insulin release in the isolated perfused rat pancreas. J Clin Invest 54: $819-832$

16. Assan R, Tchobroutsky G, Derot M (1971) Glucagon radioimmunoassay: Technical problems and recent data. Horm Metab Res 5 (Suppl 1): 82-90

17. Heding LG (1971) Radioimmunological determination of pancreatic and gut glucagon in plasma. Diabetologia 7: 10-19

18. Rosselin G, Assan R, Yalow RS, Berson SA (1966) Separation of antibody bound and unbound peptide hormones labelled with iodine 131 by talcum powder and precipitated silica. Nature 212: 355-357

19. Jarrousse C, Lardeux B, Bourdel G, Girard-Globa A, Rosselin G (1980) Portal insulin and glucagon in rats fed proteins as a meal: immediate variations and circadian modulations. J Nutrition 110 : 1764-1773

20. Karakash C, Hustvedt BE, Løvø A, Le Marchand Y, Jeanrenaud $B$ (1977) Consequences of ventromedial hypothalamic lesions on metabolism of perfused rat liver. Am J Physiol 232: E286-E293

21. Suehiro F, Chikamori K (1980) Studies on glucagon secretion in obese rats with hypothalamic lesions. Nippon-Naibunpi-GakkaiZasshi 56: 1606-1617

22. Seino $Y$, Seino $S$, Takemura J, Tsuda $K$, Nishi S, Ishida $H$, Seno M, Usami M, Ikeda M, Imura H (1984) Changes in insulin, somatostatin, and glucagon secretion during the development of obesity in ventromedial hypothalamic-lesioned rats. Endocrinology 114: $457-461$

23. Inoue S, Campfield A, Bray GA (1977) Comparison of metabolic alterations in hypothalamic and high fat diet-induced obesity. Am J Physiol 233: R162-R168

24. Chikamori K, Nishimura N, Suehiro F, Sato K, Mori H, Saito S (1980) Alterations in glucagon secretion in obese rats with hypothalamic lesions. Horm Metab Res 12: 56-59

25. Bobbioni E, Coscelli C (1980) Portal levels of glucagon and insulin in VMH-lesioned rats. Horm Metab Res 12: 480-481

26. Rohner-Jeanrenaud F, Jeanrenaud B (1981) Possible involvement of the cholinergic system in hormonal secretion by the perfused pancreas from ventromedial-hypothalamic lesioned rats. Diabetologia 20:217-222

27. Goto Y, Carpenter RG, Berelowitz M, Frohman LA (1980) Effect of ventromedial hypothalamic lesions on the secretion of somatostatin, insulin, and glucagon by the perfused rat pancreas. Metabolism 29: 986-990

28. Seino S, Seino Y, Takemura J, Tsuda K, Kuzuya H, Ishikawa K, Shimazu T, Imura H (1981) Somatostatin, insulin, and glucagon secretion from isolated perfused pancreas of obese rats. Am J Physiol 241: E146-E150

29. Karakash C, Assimacopoulos-Jeannet F, Jeanrenaud B (1976) An anomaly of insulin removal in perfused livers of obese-hyperglycemic $(o b / o b)$ mice. J Clin Invest 57: 1117-1124

Received: 15 February 1984

and in final form: 13 August 1984

Dr F. Rohner-Jeanrenaud

Laboratoires de Recherches Métaboliques

Geneva University Medical School

64 avenue de la Roseraie

$\mathrm{CH}-1211$ Geneva 4

Switzerland 